\title{
Utility of early influenza diagnosis through point-of-care testing in children presenting to an emergency department
}

Jean Li-Kim-Moy (MBBS) ${ }^{\mathrm{a}, \mathrm{b}}$, Fereshteh Dastouri (MD) ${ }^{\mathrm{a}, \mathrm{b}}$, Harunor Rashid (MD) ${ }^{\mathrm{a}, \mathrm{b}}$, Gulam Khandaker $(\mathrm{PhD})^{\mathrm{a}, \mathrm{b}, \mathrm{c}}$, Alison Kesson (PhD) ${ }^{\mathrm{b}, \mathrm{d}, \mathrm{e}}$, Mary McCaskill (FACEM) ${ }^{\mathrm{d}}$, Nicholas Wood (PhD) $)^{\mathrm{a}, \mathrm{b}, \mathrm{d}}$, Cheryl Jones $(\mathrm{PhD})^{\mathrm{b}, \mathrm{c}, \mathrm{d}, \mathrm{e}}$, Yvonne Zurynski (PhD) ${ }^{\mathrm{b}, \mathrm{f}}$, Kristine Macartney (MD) $)^{\mathrm{a}, \mathrm{b}, \mathrm{d}}$, Elizabeth J. Elliott (MD) ${ }^{\mathrm{b}, \mathrm{d}, \mathrm{f}}$ Robert Booy $(\mathrm{MD})^{\mathrm{a}, \mathrm{b}, \mathrm{d}, \mathrm{e}}$.

a National Centre for Immunisation Research and Surveillance, The Children's Hospital at Westmead, NSW, Australia

${ }^{\mathrm{b}}$ Discipline of Paediatrics and Child Health, Sydney Medical School, The University of Sydney, NSW, Australia

${ }^{c}$ Centre for Perinatal Infection Research, The Children's Hospital at Westmead, NSW, Australia

'The Children's Hospital at Westmead, NSW, Australia

${ }^{\mathrm{e}}$ Marie Bashir Institute for Infectious Diseases \& Biosecurity, University of Sydney, NSW, Australia

${ }^{\mathrm{f}}$ Australian Paediatric Surveillance Unit, Sydney, NSW, Australia

Corresponding author:

Dr Jean Li-Kim-Moy

National Centre for Immunisation Research \& Surveillance (NCIRS)

Kids Research Institute, The Children's Hospital at Westmead

Corner Hawkesbury Road and Hainsworth Street,

Westmead NSW 2145, Australia

t: (02) 98451430

f: (02) 98451418

e: jean.likimmoy@health.nsw.gov.au

Alternate corresponding author:

Professor Robert Booy

National Centre for Immunisation Research \& Surveillance (NCIRS)

Kids Research Institute, The Children's Hospital at Westmead

Corner Hawkesbury Road and Hainsworth Street,

Westmead NSW 2145, Australia

t: (02) 98451402

f: (02) 98451418

e: robert.booy@health.nsw.gov.au

Word count: 2898

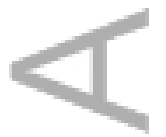

This is the author manuscript accepted for publication and has undergone full peer review but has not been through the copyediting, typesetting, pagination and proofreading process, which may lead to differences between this version and the Version of Record. Please cite this article as doi: 10.1111/jpc.13092

This article is protected by copyright. All rights reserved. 


\section{Abstract:}

\section{Background}

Influenza causes a large burden of disease in children. Point-of-care testing (POCT) can rapidly diagnose influenza with the potential to reduce investigation and hospital admission rates, but information on its use in an Australian setting is limited.

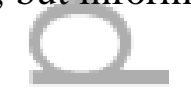

\section{Methods}

Through a retrospective review of laboratory-confirmed influenza cases presenting at a paediatric emergency department (ED) in 2009, we evaluated children diagnosed by POCT versus standard testing (direct fluorescent antibody, PCR, or viral culture) and assessed differences in investigations, admission requirements, length-of-stay (LOS) in ED/hospital, and antibiotic/antiviral prescription. The rate of serious bacterial infection (SBI) was examined.

Results

Compared to standard testing $(n=65)$, children diagnosed by positive POCT $(n=236)$ had a shorter median hospital LOS by 1 day ( $\mathrm{p}=0.006)$, increased antiviral prescription (OR 3.31, $\mathrm{p}<0.001)$ and a reduction in the time to influenza diagnosis $(2.4$ versus 24.4 hours, $\mathrm{p}<0.001)$; however a negative POCT result $(n=63)$ resulted in delayed diagnosis (44.0 hours, $p=0.001)$. POCT did not decrease LOS in ED. Interpretation of reductions in admission and investigations with POCT may be limited by possible confounding. Approximately $4 \%$ of influenza patients had a SBI; urinary tract infections were commonest $(2.7 \%)$ but no CSF cultures were positive. A single positive blood culture was seen among 332 immunocompetent influenza patients. 


\section{Conclusions}

Influenza diagnosis by POCT was quicker and reduced LOS of hospitalised children, whereas negative results delayed diagnosis. Negative POCT should not alter usual investigations if influenza remains suspected. A controlled prospective study during the influenza season is needed to clarify the direct benefits of POCT.

Words: 250

$=$

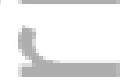

Keywords:

Influenza; children; point-of-care testing; emergency department

\section{What is allready known on this topic.}

- Influenza point of care testing (POCT) has the potential to diagnose influenza in as quickly as 10 minutes and can be performed at the bedside. It has moderate sensitivity but high specificity.

- During winter, a large proportion of young children with fever presenting to the Emergency Department (ED) may have influenza as an underlying diagnosis.

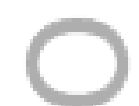

\section{What does this paper add.}

- During 2009, children diagnosed with influenza through POCT in emergency had a significantly shorter time to influenza diagnosis and for those hospitalised, spent a median of one less day in hospital compared with those diagnosed through standard means. Additional findings included increased antiviral prescription for those who were diagnosed by POCT. 
- False negative POCT delayed influenza diagnosis. POCT's moderate sensitivity means that negative results should prompt ED clinicians to use other confirmatory tests to avoid diagnostic delays or to confidently exclude influenza.

- Concurrent serious bacterial infection is low in influenza-positive patients but urinary tract infections need to be excluded.

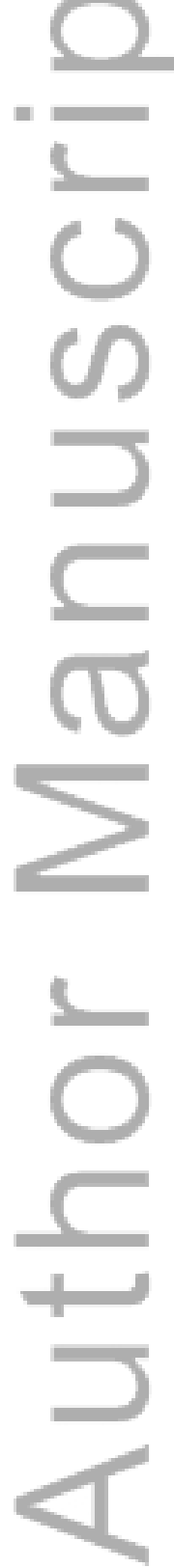

This article is protected by copyright. All rights reserved. 


\section{Introduction:}

It is increasingly recognised that influenza causes a significant burden of disease in children, and that this is skewed towards the very young. ${ }^{1-3}$ During the winter epidemic season, up to $50 \%$ of febrile children aged $<36$ months presenting to the Emergency Department (ED) test positive for influenza. ${ }^{4}$ Hospitalisation rates of up to 270 per 100,000 in infants aged $<6$ months occur, often to cover the possibility of serious bacterial illness (SBI). ${ }^{5}$ Diagnostic uncertainly often necessitates invasive investigations such as lumbar puncture (LP), blood culture (BC), and sterile urine sampling., 3,7

Point-of-care testing (POCT) for influenza is an important method for rapid diagnosis which may impact on decisions regarding ED patient investigation and management. Previous studies have provided conflicting results on possible benefits of POCT in terms of assessment time in the ED, ancillary testing, and antibiotic/antiviral prescription. ${ }^{8-15}$ There are no Australian studies evaluating whether POCT facilitates earlier diagnosis of influenza in children or affects length-of-stay (LOS) in the ED/hospital or the rate of hospitalisation. In addition no study has addressed the delay in diagnosis which might be prevented through the use of POCT.

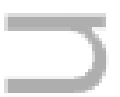

We therefore sought to compare children who were diagnosed with influenza through POCT or standard means at a tertiary paediatric hospital during 2009, a pandemic influenza season, to assess the impact of POCT on hospitalisation rates, LOS, rates of invasive investigation, 
and prescription of antibiotics/antivirals. We also documented the risk of concurrent serious bacterial illness at the time of presentation with influenza.

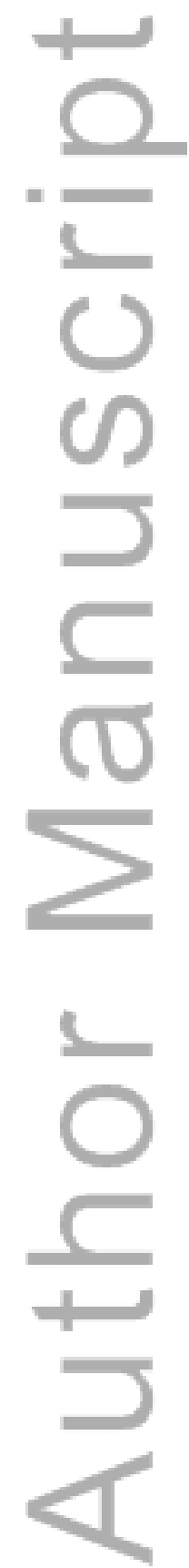

This article is protected by copyright. All rights reserved. 


\section{Materials and Methods:}

We performed a retrospective review of influenza presentations at The Children's Hospital at Westmead, during the $2009 \mathrm{H} 1 \mathrm{~N} 1$ pandemic influenza season when POCT was first routinely used in our hospital. Our study included laboratory-proven influenza cases aged $0-<18$ years, diagnosed between January 1 and December 31, 2009, through POCT or "standard" testing (i.e. direct fluorescent antibody testing [DFA], viral culture, or nucleic acid testing by polymerase chain reaction [PCR]). We used data partly from a prospective study by the Paediatric Active Enhanced Disease Surveillance System (PAEDS) of influenza admissions at our hospital between June 1 and September 30, 2009, which was funded by the National Health and Medical Research Council (NHMRC). ${ }^{16}$ Retrospectively, additional cases were ascertained through a search of the hospital virology database and consisted of non-admitted children or children presenting outside the June-September period. Some retrospective data were collected on PAEDS cases including assessment times in ED and investigations performed. We excluded cases without an ED presentation and possible nosocomial cases that were tested more than 72 hours after first presentation to ED.

1

All patients had a nasopharyngeal aspirate (NPA) or nasal/throat swab performed. As part of the CONTAIN phase of the 2008 Australian Health Management Plan for Pandemic Influenza (AHMPPI), ${ }^{17}$ there was an emphasis on early detection of cases through testing to allow for effective isolation of cases, to limit spread of infection, and to allow prescription of antiviral medications. POCT was therefore routinely used after the onset of the pandemic, as the first-line influenza test. The treating ED clinician ordered POCT or DFA at their 
discretion. Physicians were aware, through a hospital influenza pandemic plan, of the limited sensitivity and high specificity of the test and the need for referral for further testing when results were negative. The availability of testing and the time to a result guided physicians' choice of test. POCT (QuickVue Influenza A+B immunochromatographic test, Quidel Corp., San Diego, CA, USA) was performed 24 hours a day in the virology laboratory to ensure test standardisation and correct interpretation, with results taking a minimum of 20 minutes. DFA for respiratory viruses (Similfluor respiratory screen, Chemicon, CA) was batched and performed twice per day. Influenza-positive POCT had no further testing. Negative POCT specimens underwent DFA, those negative by DFA had viral culture and PCR testing.

\section{Data collection and analysis:}

Review of all case records sourced from PAEDS notifications and the virology database was performed. Data were collected on medical history e.g. presence of comorbidities predisposing to severe influenza ${ }^{18}$, ED clinical parameters, the assessment time in the ED, and the following outcome measures: a) rates of particular investigations (lumbar puncture, blood culture, or sterile urine collection); b) serious bacterial illness (SBI), defined as a positive culture with a pathogenic or clinically significant organism from a normally sterile site (CSF, blood, or urine); c) antibiotic/antiviral prescription; and d) admission to hospital and/or the intensive care unit (ICU). We investigated the effect of a positive POCT test by comparing children diagnosed with influenza by POCT (POCT-positive group) with children in whom it was not performed (No-POCT group, standard testing), and made further comparisons with children who had a negative POCT despite having influenza infection confirmed by other means (POCT-negative group). We also explored the effect of the time to 
influenza diagnosis (from seeing the ED doctor to the influenza result being available) on the above outcomes.

\section{Statistical methods.}

Continuous variables between groups were compared using independent samples t-tests and categorical outcomes with the Chi-Square test or Fisher's exact test. Non parametric distributions were compared using a Mann Whitney U test. We performed univariate and multivariate analysis using logistic regression or generalised linear models to investigate associations between results of POCT and measured outcomes. We included possible confounding factors, namely age (as a continuous variable), sex, total time in ED (from commencement of medical assessment to discharge home or to the ward), presence of comorbidities, time and day of presentation, and ED variables: highest recorded temperature, pulse rate, respiratory rate, and lowest oxygen saturation as covariates. Odds ratios or ratios of means were calculated and p values $\leq 0.05$ were considered significant. All analyses were performed using IBM SPSS Statistics 21 (Inc, Somers, NY, USA).

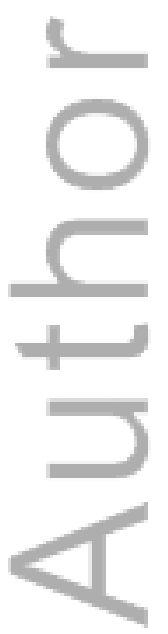




\section{Results:}

From 411 positive influenza results, duplicate results and non-ED presentations were excluded, leaving 364 eligible patients. Males accounted for $60 \%$ of all patients $(\mathrm{p}<0.001)$ The median age was 3.1 years (interquartile range 1.1-7.4) with a marked skew towards younger children (Figure 1). The majority of influenza patients were healthy with only $32 \%$ having a history of comorbidity, and $66 \%$ of presentations occurred during daytime hours (08:00-20:00 hours).

The majority of patients underwent POCT $(82.1 \%, \mathrm{n}=299)$. Of these, 236 patients tested positive and formed the POCT-positive group. About 21\% (n=63) of POCT tests were falsely negative and formed the POCT-negative group (Figure 2), and 65 patients had standard testing (No-POCT group). We could not assess the sensitivity or specificity of POCT, as confirmatory testing was only performed if POCT was negative. Four of 236 patients (1.7\%) in the POCT-positive influenza group had negative confirmatory PCR testing possibly indicating false positive results. None of these patients was diagnosed with SBI.

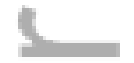

Demographic and clinical details were similar for children in the POCT-positive and POCTnegative groups compared with the No-POCT group (Tables 1,2). There were no differences in gender distribution, proportion of daytime or weekend presentations, presence of comorbidity, or rate of ICU admission.

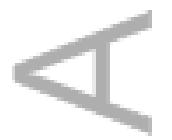

This article is protected by copyright. All rights reserved. 
Children in the POCT-positive group, compared with the No-POCT group, had a slightly but statistically significantly higher maximum temperature during their ED presentations (Table 1). In the POCT-positive group, median hospital length-of-stay (LOS) was significantly shorter by one day and children had a significantly shorter median time to influenza diagnosis (2.4 versus 24.4 hours, $\mathrm{p}<0.001$ ). The multivariate logistic regression analysis looking at the outcome of LOS $\leq 1$ day confirmed a significant association with positive POCT (OR 4.23, 5\% CI 1.53-11.7; $\mathrm{p}=0.006)$. The median LOS in ED was similar between groups.

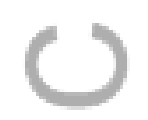

In univariate analysis of categorical outcomes (Table 1), fewer patients in the POCT-positive group, compared with the No-POCT group, were admitted, or required antibiotics or BC, but antiviral prescription was significantly higher in the POCT-positive group. In the multivariate logistic regression model, positive POCT remained significantly associated with a reduced admission rate $(\mathrm{OR} 0.18, \mathrm{p}=0.001)$, increased antiviral prescription $(\mathrm{OR} 4.54, \mathrm{p}<0.001)$, and reduced collection of $\mathrm{BC}(\mathrm{OR} 0.38, \mathrm{p}=0.02)$.

We then compared the POCT-negative group (influenza-positive by alternative tests) with the No-POCT group (Table 2) to examine for effects seen only with positive POCT. Children who were POCT-negative were older, and as a result had lower mean respiratory rates than those who had standard testing. They had a significantly longer median time to influenza diagnosis (44.0 versus 24.4 hours, $\mathrm{p}=0.001$ on multivariate analysis). Furthermore the absence of differences in antiviral prescription and LOS of hospitalised patients in multivariate regression analyses compared with the POCT-positive analysis suggested these effects to be more closely related to the POCT result. The lower rates of admission (OR 0.25 , 
$\mathrm{p}=0.009)$ and blood culture (OR 0.31, $\mathrm{p}=0.01)$ in those with a negative POCT result were similar to the POCT-positive multivariate analysis and may have indicated influence by factors other than POCT.

Analysis of all patients revealed that $4.1 \%$ of influenza-diagnosed patients assessed in ED required ICU admission, 58\% had blood cultures performed and $4.7 \%$ had a lumbar puncture. Invasive investigations, urine culture, and admissions were all most common in those aged $<3$ months (BC 79\%, LP 25\%, and admissions 71\%, table 3).

Serious bacterial infection: (Table 3)

Overall, the rate of SBI was low at $4.1 \%$, with urinary tract infections (UTIs) predominating $(2.7 \%)$. UTI rates were highest in infants aged $<3$ months $(8.3 \%)$. Positive BCs were found in $5(1.4 \%)$ influenza patients but four were immunocompromised and were treated for infections normally considered non-pathogenic or contaminants (e.g. coagulase negative staphylococcus, viridans streptococci). The one patient (from 332 immunocompetent individuals) with a positive $\mathrm{BC}$, had a non-typeable Haemophilus influenza bacteraemia. No LPs were positive for bacterial or viral pathogens.

Time to influenza diagnosis:

After allocating all patients to "time to influenza diagnosis" time bands $(0-<2,2-<4,4-<8$ and 8-<72 hours), unadjusted analysis showed a positive association between increased time to diagnosis and proportions of patients requiring admission, antibiotic prescription and $\mathrm{BCs}$ (Figure 3). In a logistic regression model, the variable "time to influenza diagnosis time" (in 
hours) remained significantly associated only with hospital admission (OR 1.01, 95\% CI 1.00$1.03, \mathrm{p}=0.02)$ and decreased antiviral prescription (OR 0.97, 95\%CI 0.96-0.99, $\mathrm{p}<0.001)$.

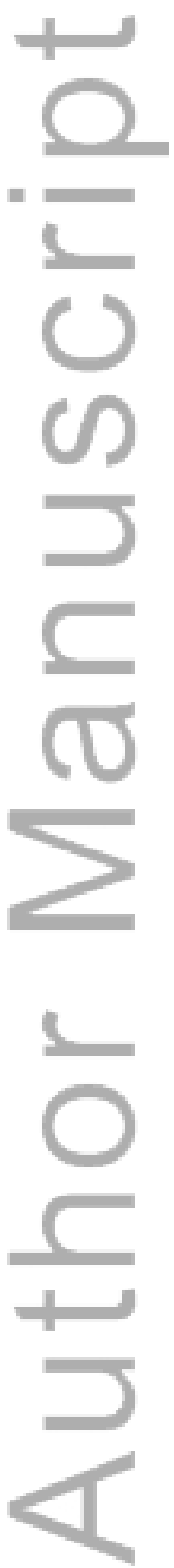

This article is protected by copyright. All rights reserved. 


\section{Discussion:}

The 2009 pandemic was the first influenza season at our tertiary paediatric hospital, in which POCT was used extensively to aid rapid diagnosis of influenza as part of the enactment of the Australian Health Management Plan for Pandemic Influenza. This study has shown significant differences in outcomes in children with laboratory-confirmed influenza presenting to ED and diagnosed with POCT compared with standard testing (No-POCT). However, the retrospective nature of data analysis and our inability to exclude all confounders limited the interpretation of some findings.

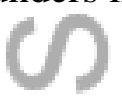

Our analyses show that whilst positive POCT was associated with multiple significant potential benefits compared to standard testing, not all could be attributed solely to the positive result. Diagnosis by POCT was associated with reduced LOS in hospitalised children and we hypothesise that this is related to the significant reduction in the median time to influenza diagnosis. In addition, positive POCT led to significantly higher rates of antiviral prescription. There was no benefit of a POCT-positive test in reducing LOS in ED.

\section{$\underline{1}$}

The reduced need for hospital admissions and blood cultures was apparent in both the POCTpositive and POCT-negative children, making the interpretation of these results difficult. A separate analysis suggested that the time to influenza diagnosis was independently and significantly associated with the rate of hospital admission and the frequency of antiviral medication prescription. As POCT significantly reduces the time to influenza diagnosis, it is possible that a true relationship between POCT and reduced admission rates exists, but could 
not be demonstrated due to confounding. Nevertheless, it appears that the timeliness of POCT to reach an influenza diagnosis is beneficial.

It is noteworthy that the POCT-negative group had a significantly longer time to influenza diagnosis. This suggests that false negative results may have decreased suspicion of influenza, delaying alternative testing and the subsequent diagnosis of influenza.

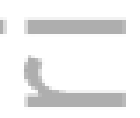

Our findings that POCT-positive patients were younger and had higher mean maximum temperature in ED compared with No-POCT patients may be due to differences in test sensitivity according to age or clinical presentation. There may have been increased testing of young infants or children who appeared more unwell, or possibly higher sensitivity of POCT in children with higher fever which is a potential indicator of greater viraemia and viral shedding. Research by another group at our hospital during the same season demonstrated that the POCT used in our study had a high overall sensitivity (79.2\%) and excellent specificity (98.4-100\%). ${ }^{19}$ They also found the use of NPA, the predominant sampling type in our study, achieved a higher sensitivity than swabs for children $<5$ years of age $(88.9 \%$ $91.7 \%)$ and children $\geq 5$ years old $(66.7 \%)$.

Given our findings of delayed influenza diagnosis with false-negative POCT, it is important that clinicians are aware that POCT sensitivity is moderate, usually $<80 \%$, hence negative results warrant further investigation for influenza if suspicion is high. The high specificity of POCT ensures few non-influenza patients will be incorrectly labelled as influenza-positive and potentially under-investigated. 
Previous reports of the use of POCT in ED settings have given mixed results depending on the groups compared, with clearer benefits in influenza-positive subgroups. Two randomised controlled trials (RCTs) involving children of all ages, have shown a significant reduction in the requirement for blood tests and antibiotics in influenza-positive patients if POCT was performed. $^{10,12}$ One of these studies found further benefits with reduction in both LOS in ED and costs to the patient. ${ }^{10}$ Conversely, other RCTs or quasi-RCTs in young febrile children aged $<24$ or 36 months, ${ }^{11,13}$ have not shown consistent benefits of POCT over routine testing. ()

Observational studies ${ }^{8,9,14}$ have suggested reduced investigation rates, and lower rates of SBI in patients with a positive POCT, but potential confounding exists due to the known lower risk of SBI in influenza-positive patients. ${ }^{20,21}$ A recent retrospective US study on the impact of POCT on clinical care in the ED, concluded that influenza diagnoses by POCT were associated with significant reductions in ancillary testing, antibiotic prescription, and increased antiviral prescription. ${ }^{15}$

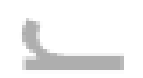

Importantly, we found low rates of concurrent serious bacterial infection (SBI) in children with laboratory-confirmed influenza. Positive blood cultures were rare, especially in influenza-infected children without immunosuppression. No positive CSF cultures were recorded in our study. Urinary tract infections made up the majority of bacterial coinfections; therefore despite a positive influenza diagnosis, it remains important that UTI be excluded especially in children $<1$ year of age. 
Our findings support previous studies which found low rates of concurrent SBI in young children with influenza. ${ }^{14,20,21}$ These studies used POCT to diagnose influenza and documented a rate of SBI of $1.8 \%$ in influenza-positive children aged $0-36$ months $^{21}$ and rates of $2.5-2.65 \%$ for children $<3$ months of age. ${ }^{14,20}$ Our SBI rate $(4.1 \%)$ was higher, potentially due to inclusion of children with pre-existing medical conditions and immunosuppression. Furthermore, the cited studies found significantly reduced rates of SBI in influenza-positive compared with influenza-negative children. ${ }^{14,20,21}$ Given these findings, we hypothesise that rapid diagnosis of influenza by POCT could assist in stratifying children into a lower risk group for SBI and thereby potentially decrease the need for invasive investigations, and assist in making decisions for outpatient management. This indication for POCT deserves further study in the current age of much reduced rates of occult bacteraemia due to the implementation of vaccines for Haemophilus influenzae type b and pneumococcus. ${ }^{22-26}$

\section{Limitations and strengths:}

Our study was limited in being an observational study of ED presentations, with partial retrospective data collection. Many children presenting to ED in 2009 were diagnosed with influenza clinically without laboratory confirmation, and were not included in our study. Also, we investigated only those with confirmed influenza rather than all children who had presented with fever; the benefits of POCT in the latter group requires further investigation. The results of our study may not be generalisable to non-pandemic seasons, as patterns of POCT use may be different. As we did not review subsequent ED presentations, we were unable to comment on the incidence of secondary bacterial infections after discharge. 
The potential for unknown confounding must be borne in mind due to the lack of information about the treating clinicians' reasons for performing POCT, their interpretation of results, and underlying differences in study groups. Associations must be interpreted with caution and serve to guide further study into the role of POCT in the ED.

We did not evaluate the cost-effectiveness of POCT. While the cost per specimen is higher with POCT than DFA, this does not take into account potential savings from earlier diagnosis or reduced LOS. There are no studies which evaluate the cost benefit of POCT over standard testing in a paediatric hospital setting. This would need to be considered in any decisionmaking process for more widespread use of POCT in the paediatric ED setting.

\section{Conclusion:}

POCT is associated with a more timely diagnosis of influenza in paediatric ED patients, decreased hospital LOS, and increased use of potentially effective antiviral medication. SBI appears uncommon in influenza-positive patients; therefore whether rapid confirmation of influenza is useful in risk stratification for SBI in young children presenting with fever during winter deserves further study. Importantly, a negative POCT test does not confirm the absence of influenza and ED clinicians should use other confirmatory tests to avoid diagnostic delays or to confidently exclude influenza. While useful benefits are suggested by our study, a future randomised controlled study of POCT during the annual influenza season, with cost-benefit analyses, is needed to clarify the benefits of POCT. 


\section{Acknowledgements:}

Acknowledgement is made of the assistance of Lakmitha Supun Gunatilake and Dharshana

Sabanayagam who assisted greatly with data entry for this study and all clinicians

contributing cases to PAEDS. Elizabeth Elliott is supported by a Practitioner Fellowship from the National Health and Medical Research Council (NHMRC) of Australia. The PAEDS pandemic influenza project was funded by the NHMRC (Project Grant No. 633028).

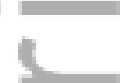

\section{Conflict of interest statement}

R. Booy has received funding from bioCSL, Roche, Sanofi, GlaxoSmithKline (GSK),

Novartis, and Pfizer to conduct sponsored research or attend and present at scientific

meetings; any funding received is directed to a research account at the Children's Hospital at Westmead.

\section{Glossary/Acronyms:}

BC: Blood culture

CSF: Cerebrospinal fluid

DFA: Direct fluorescent antibody

ED: Emergency department

LOS: Length-of-stay

LP: Lumbar puncture

NPA: Nasopharyngeal aspirate

POCT: Point of care testing 
SBI: Serious bacterial infection

UTI: Urinary tract infection

\section{Figure Legends:}

Figure 1: Age distribution of all influenza patients. Numbers of presentations by 6 month age bands

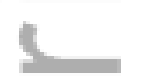

Figure 2: Method of diagnosis in influenza patients. Numbers of patients in brackets. $(+)$ positive result, (-) negative result

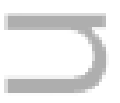

Figure 3: Outcome measures by "time to influenza diagnosis" time bands in all patients.

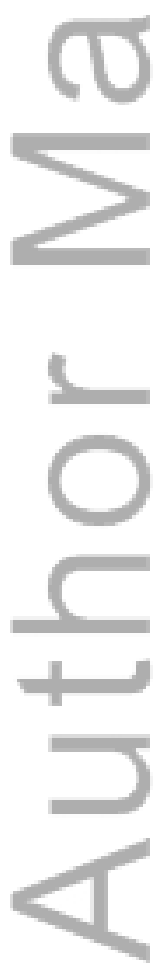

This article is protected by copyright. All rights reserved. 
Table 1: Demographics, clinical details and outcome measures of influenza patients diagnosed by positive POCT or standard testing (No POCT). Results of univariate and multivariate analysis of the effect of positive POCT on outcomes. Comparisons in bold are significantly different between corresponding groups.

\begin{tabular}{|c|c|c|c|c|c|c|}
\hline & \multicolumn{4}{|c|}{ Univariate model } & \multicolumn{2}{|c|}{ Multivariate model } \\
\hline & $\begin{array}{l}\text { POCT Positive } \\
\quad(\mathrm{n}=236)\end{array}$ & $\begin{array}{l}\text { No POCT } \\
(\mathrm{n}=65)\end{array}$ & OR (95\%CI) & p-value & $\begin{array}{l}\text { OR or ratio of } \\
\text { mean time } \\
(95 \% \mathrm{CI})\end{array}$ & $\overline{p \text {-value }}$ \\
\hline \multicolumn{7}{|l|}{$\begin{array}{l}\text { Demographics and } \\
\text { Clinical details }\end{array}$} \\
\hline Male (\%) & 58.5 & 67.7 & - & 0.18 & - & - \\
\hline $\begin{array}{l}\text { Median Age in years } \\
\text { (IQR) }\end{array}$ & $2.39(0.96-6.33)$ & $3.49(0.94-7.79)$ & - & $0.40^{*}$ & - & - \\
\hline $\begin{array}{l}\text { Mean Highest } \\
\text { Temperature in ED } \\
\left({ }^{\circ} \mathrm{C}\right)\end{array}$ & 38.6 & 38.2 & - & 0.004 & - & - \\
\hline $\begin{array}{l}\text { Mean Highest Pulse } \\
\text { Rate in ED (/min) }\end{array}$ & 149 & 143 & - & 0.20 & - & - \\
\hline $\begin{array}{l}\text { Mean Highest Resp } \\
\text { Rate in ED (/min) }\end{array}$ & 35.8 & 34.7 & - & 0.53 & - & - \\
\hline $\begin{array}{l}\text { Mean Lowest } \\
\text { Saturations }(\%)\end{array}$ & 96.6 & 95.9 & - & 0.27 & - & - \\
\hline $\begin{array}{l}\text { Comorbidity present \% } \\
\text { (n) }\end{array}$ & $28.4(67)$ & $40.0(26)$ & - & 0.07 & - & - \\
\hline $\begin{array}{l}\text { Weekend presentation } \\
\%(\mathrm{n})\end{array}$ & $27.1(64)$ & $21.5(14)$ & - & 0.36 & - & - \\
\hline $\begin{array}{l}\text { Daytime presentation } \\
8: 00-20: 00 \text { hrs \% (n) }\end{array}$ & $63.1(149)$ & $73.8(48)$ & - & 0.11 & - & - \\
\hline $\begin{array}{l}\text { Night-time } \\
\text { presentation 20:00- } \\
8: 00 \text { hrs \% (n) }\end{array}$ & $36.9(87)$ & $26.2(17)$ & - & 0.11 & - & - \\
\hline \multicolumn{7}{|l|}{ Outcomes } \\
\hline $\begin{array}{l}\text { Median LOS in days if } \\
\text { admitted (IQR) }\end{array}$ & $2(1-3)$ & $3(2-4)$ & - & $0.001^{*}$ & $4.23(1.53-11.7)^{\ddagger}$ & 0.006 \\
\hline $\begin{array}{l}\text { Median total time in } \\
\text { ED in hours if } \\
\text { admitted (IQR) }\end{array}$ & $6.1(4.3-10.2)$ & $6.0(4.9-9.8)$ & - & 0.74 & NP & NP \\
\hline $\begin{array}{l}\text { Median total time in } \\
\text { ED in hours if } \\
\text { discharged (IQR) }\end{array}$ & $2.7(1.7-4.1)$ & $2.4(1.9-3.1)$ & - & 0.53 & NP & $\mathrm{NP}$ \\
\hline $\begin{array}{l}\text { Median total time to } \\
\text { influenza diagnosis in } \\
\text { hours (IQR) }\end{array}$ & $2.4(1.7-4.3)$ & $24.4(18.1-44.0)$ & - & $<0.001^{*}$ & $0.46(0.42-0.50)^{\S}$ & $<0.001$ \\
\hline Admission \% (n) & $50.0(118)$ & $81.5(53)$ & $0.23(0.12-0.45)$ & $<0.001$ & $0.18(0.07-0.48)^{\dagger}$ & 0.001 \\
\hline ICU admission \% (n) & $3.0(7)$ & $4.6(3)$ & $1.58(0.40-6.3)$ & 0.52 & NP & NP \\
\hline $\begin{array}{l}\text { Antibiotics Prescribed } \\
\% \text { (n) }\end{array}$ & $33.1(78)$ & $53.8(35)$ & $0.42(0.24-0.74)$ & 0.003 & $0.57(0.28-1.14)^{\dagger}$ & 0.11 \\
\hline $\begin{array}{l}\text { Antiviral prescribed \% } \\
\text { (n) }\end{array}$ & 46.2 (109) & 21.5 & $3.13(1.64-5.96)$ & 0.001 & $4.54(2.00-10.3)^{\dagger}$ & $<0.001$ \\
\hline LP performed \% (n) & $4.7(11)$ & $4.6(3)$ & $1.01(0.27-3.73)$ & 0.99 & NP & NP \\
\hline $\begin{array}{l}\text { Blood culture } \\
\text { performed } \%(n)\end{array}$ & $54.2(128)$ & $76.9(50)$ & $0.36(0.19-0.67)$ & 0.001 & $0.38(0.17-0.86)^{\dagger}$ & 0.02 \\
\hline $\begin{array}{l}\text { Urine culture } \\
\text { performed } \%(\mathrm{n})\end{array}$ & $22.9(54)$ & $26.2(17)$ & $0.84(0.45-1.58)$ & 0.58 & NP & NP \\
\hline $\begin{array}{l}\text { Invasive urine } \\
\text { collection } \%(\mathrm{n})\end{array}$ & $12.3(29)$ & $7.7(5)$ & $1.68(0.62-4.53)$ & 0.31 & $\mathrm{NP}$ & NP \\
\hline
\end{tabular}

Abbreviations: CI, Confidence interval; ED; Emergency Department; ICU, intensive care unit; IQR, interquartile range; LOS, length of stay; LP, lumbar puncture; NP, not performed; OR, odds ratio; POCT, point-of-care testing.

* Distribution assessed using Mann Whitney U test.

${ }^{\dagger}$ Multivariate logistic regression model for the effect of POCT adjusted for following covariates (age, sex, highest temperature, highest HR, highest RR, lowest oxygen saturations, total time in ED, presence of comorbidity, daytime presentation, weekend presentation). Result indicates adjusted OR. 
${ }^{\ddagger}$ Multivariate logistic regression performed for the effect of POCT on outcome of length of stay $\leq 1$ day, adjusted for following covariates (age, sex, highest temperature, highest HR, highest RR, lowest oxygen saturations, total time in ED, presence of comorbidity, daytime presentation, weekend presentation). Result indicates adjusted OR.

${ }^{\S}$ Generalised linear model using log transformed data (time in hours +1 ) for the effect of POCT adjusted for following factors/covariates (age, sex, highest temperature, highest HR, highest RR, lowest oxygen saturations, total time in ED, presence of comorbidity, daytime presentation, weekend presentation). Result indicates ratio of mean total time with a positive POCT result compared with mean total time with No-POCT.

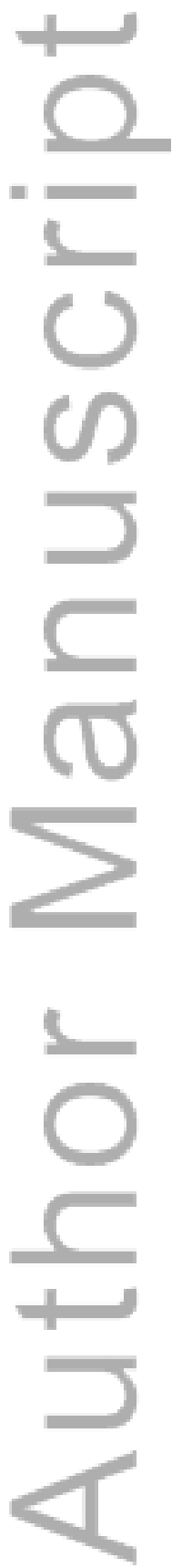


Table 2: Demographics, clinical details and outcome measures of influenza patients with negative POCT result (POCT-negative) or standard testing (No-POCT). POCT-negative patients were, by definition, influenza positive but diagnosed by an alternative test. Results of univariate and multivariate analysis of the effect of negative POCT on outcomes. Comparisons in bold are significantly different between corresponding groups.

\begin{tabular}{|c|c|c|c|c|c|c|}
\hline & \multicolumn{4}{|c|}{ Univariate model } & \multicolumn{2}{|c|}{ Multivariate model } \\
\hline & $\begin{array}{l}\text { POCT-Negative } \\
(\mathrm{n}=63)\end{array}$ & $\begin{array}{l}\text { No POCT } \\
(\mathrm{n}=65)\end{array}$ & OR (95\%CI) & p-value & $\begin{array}{l}\text { OR or ratio of } \\
\text { mean time } \\
(95 \% \mathrm{CI})\end{array}$ & p-value \\
\hline \multicolumn{7}{|l|}{$\begin{array}{l}\text { Demographics and } \\
\text { Clinical details }\end{array}$} \\
\hline Male (\%) & 60.3 & 67.7 & - & 0.39 & - & - \\
\hline $\begin{array}{l}\text { Median Age in years } \\
\text { (IQR) }\end{array}$ & $5.43(2.18-5.44)$ & $3.49(0.94-7.79)$ & - & $0.009^{*}$ & - & - \\
\hline $\begin{array}{l}\text { Mean Highest } \\
\text { Temperature in ED } \\
\left({ }^{\circ} \mathrm{C}\right)\end{array}$ & 38.2 & 38.2 & - & 0.77 & - & - \\
\hline $\begin{array}{l}\text { Mean Highest Pulse } \\
\text { Rate in ED (/min) }\end{array}$ & 134 & 143 & - & 0.08 & - & - \\
\hline $\begin{array}{l}\text { Mean Highest Resp } \\
\text { Rate in ED (/min) }\end{array}$ & 30.4 & 34.7 & - & 0.04 & - & - \\
\hline $\begin{array}{l}\text { Mean Lowest } \\
\text { Saturations }(\%)\end{array}$ & 96.9 & 95.9 & - & 0.14 & - & - \\
\hline $\begin{array}{l}\text { Comorbidity present } \% \\
\text { (n) }\end{array}$ & $38.1(24)$ & $40.0(26)$ & - & 0.83 & - & - \\
\hline $\begin{array}{l}\text { Weekend presentation } \\
\%(\mathrm{n})\end{array}$ & $27.0(17)$ & $21.5(14)$ & - & 0.47 & - & - \\
\hline $\begin{array}{l}\text { Daytime presentation } \\
8: 00-20: 00 \mathrm{hrs} \% \text { (n) }\end{array}$ & $66.7(42)$ & $73.8(48)$ & - & 0.37 & - & - \\
\hline $\begin{array}{l}\text { Night-time } \\
\text { presentation 20:00-8:00 } \\
\text { hrs } \%(n)\end{array}$ & $33.3(21)$ & $26.2(17)$ & - & 0.37 & - & - \\
\hline \multicolumn{7}{|l|}{ Outcomes } \\
\hline $\begin{array}{l}\text { Median LOS in day } \\
\text { admitted (IQR) }\end{array}$ & $3(1.5-8.5)$ & $3(2-4)$ & - & $0.50^{*}$ & $1.25(0.33-4.69)^{\ddagger}$ & 0.75 \\
\hline $\begin{array}{l}\text { Median total time in } \\
\text { ED in hours if } \\
\text { admitted (IQR) }\end{array}$ & $4.9(2.9-6.5)$ & $6.0(4.9-9.8)$ & - & $0.03^{*}$ & $0.97(0.86-1.08)^{\S}$ & 0.55 \\
\hline $\begin{array}{l}\text { Median total time in } \\
\text { ED in hours if } \\
\text { discharged (IQR) }\end{array}$ & $2.8(2.2-4.4)$ & $2.4(1.9-3.1)$ & - & $0.14^{*}$ & NP & NP \\
\hline $\begin{array}{l}\text { Median total time to } \\
\text { influenza diagnosis in } \\
\text { hours (IQR) }\end{array}$ & $44.0(18.3-73.1)$ & 24.4(18.1-44.0) & - & $0.04^{*}$ & $1.25(1.10-1.42)^{\S}$ & 0.001 \\
\hline Admission $\%(\mathrm{n})$ & $46.0(29)$ & $81.5(53)$ & $0.19(0.09-0.43)$ & $<0.001$ & $0.25(0.09-0.70)^{\dagger}$ & 0.009 \\
\hline ICU admission \% (n) & $7.9(5)$ & $4.6(3)$ & $0.56(0.13-2.46)$ & 0.44 & NP & NP \\
\hline $\begin{array}{l}\text { Antibiotics Prescribed } \\
\% \text { (n) }\end{array}$ & $42.9(27)$ & $53.8(35)$ & $0.64(0.32-1.29)$ & 0.22 & NP & NP \\
\hline $\begin{array}{l}\text { Antiviral prescribed } \% \\
\text { (n) }\end{array}$ & $23.8(15)$ & $21.5(14)$ & $1.14(0.50-2.61)$ & 0.76 & NP & NP \\
\hline LP performed \% (n) & $4.8(3)$ & $4.6(3)$ & $1.03(0.20-5.32)$ & 0.97 & NP & NP \\
\hline $\begin{array}{l}\text { Blood culture } \\
\text { performed } \%(\mathrm{n})\end{array}$ & $50.8(32)$ & $76.9(50)$ & $0.31(0.15-0.66)$ & 0.002 & $0.31(0.13-0.78)^{\dagger}$ & 0.01 \\
\hline $\begin{array}{l}\text { Urine culture } \\
\text { performed \% (n) }\end{array}$ & $22.2(14)$ & $26.2(17)$ & $0.81(0.36-1.82)$ & 0.60 & NP & NP \\
\hline $\begin{array}{l}\text { Invasive urine } \\
\text { collection } \%(\mathrm{n})\end{array}$ & $6.3(4)$ & $7.7(5)$ & $0.81(0.21-3.18)$ & 0.77 & NP & NP \\
\hline
\end{tabular}

Abbreviations: CI, Confidence interval; ED; Emergency Department; ICU, intensive care unit; IQR, interquartile range; LOS, length of stay; LP, lumbar puncture; NP, not performed; OR, odds ratio; POCT, point-of-care testing.

* Distribution assessed using Mann Whitney U test. 
${ }^{\dagger}$ Multivariate logistic regression model for the effect of POCT adjusted for following covariates (age, sex, highest temperature, highest HR, highest RR, lowest oxygen saturations, total time in ED, presence of comorbidity, daytime presentation, weekend presentation). Result indicates adjusted OR.

${ }^{\ddagger}$ Multivariate logistic regression performed for the effect of POCT on outcome of length of stay $\leq 1$ day, adjusted for following covariates (age, sex, highest temperature, highest HR, highest RR, lowest oxygen saturations, total time in ED, presence of comorbidity, daytime presentation, weekend presentation). Result indicates adjusted OR.

${ }^{\S}$ Generalised linear model using log transformed data (time in hours +1 ) for the effect of POCT adjusted for following factors/covariates (age, sex, highest temperature, highest HR, highest RR, lowest oxygen saturations, total time in ED [not used in ED LOS analysis], presence of comorbidity, daytime presentation, weekend presentation). Result indicates ratio of mean total time with a negative POCT result compared with mean total time with No-POCT.

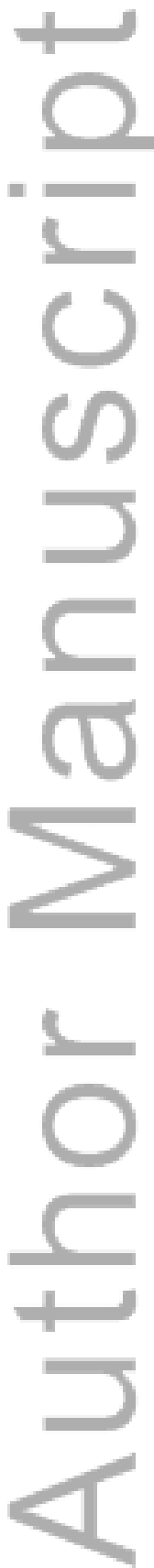

This article is protected by copyright. All rights reserved. 
Table 3: Outcome measures, investigations, and serious bacterial infection in influenza patients by age subgroups.

\begin{tabular}{|c|c|c|c|c|c|c|}
\hline & \multicolumn{6}{|c|}{$\begin{array}{c}\text { Influenza group } \\
(\mathrm{n}=\mathbf{3 6 4})\end{array}$} \\
\hline & $\begin{array}{c}<3 \text { months } \\
(n=24)\end{array}$ & $\begin{array}{c}\text { 3-11 months } \\
(\mathrm{n}=61)\end{array}$ & $\begin{array}{c}1-2 \text { years } \\
(\mathrm{n}=96)\end{array}$ & $\begin{array}{c}\geq 3-8 \text { years } \\
(\mathrm{n}=111)\end{array}$ & $\begin{array}{c}\geq 9-18 \text { years } \\
(\mathrm{n}=72)\end{array}$ & TOTAL $(n=364)$ \\
\hline \multicolumn{7}{|l|}{ Outcomes } \\
\hline Admission \% (n) & $70.8(17)$ & $57.4(35)$ & $59.4(57)$ & $54.1(60)$ & $43.1(31)$ & $54.9(200)$ \\
\hline ICU admission \% (n) & $4.2(1)$ & $6.6(4)$ & $1.0(1)$ & $7.2(8)$ & $1.4(1)$ & $4.1(15)$ \\
\hline Antibiotics Prescribed \% (n) & $50.0(12)$ & $36.1(22)$ & $43.8(42)$ & $38.7(43)$ & $29.2(21)$ & $38.5(140)$ \\
\hline \multicolumn{7}{|l|}{ Investigations } \\
\hline POCT $\%(n)^{\mathrm{e}}$ & $83.3(20)$ & $77.0(47)$ & $87.5(84)$ & $80.2(89)$ & $81.9(59)$ & $82.1(299)$ \\
\hline Blood culture \% (n) & $79.2(19)$ & $52.5(32)$ & $58.3(56)$ & $59.5(66)$ & $51.4(37)$ & $57.7(210)$ \\
\hline LP \% (n) & $25.0(6)$ & $9.8(6)$ & $2.1(2)$ & $2.7(3)$ & 0 & $4.7(17)$ \\
\hline Urine culture $\%(\mathrm{n})$ & $62.5(15)$ & $32.8(20)$ & $16.7(16)$ & $19.8(22)$ & $16.7(12)$ & $23.4(85)$ \\
\hline Invasive urine culture $\%$ (n) ${ }^{*}$ & $54.2(13)$ & $23.0(14)$ & $9.4(9)$ & $0.9(1)$ & $1.4(1)$ & $10.4(38)$ \\
\hline \multicolumn{7}{|l|}{ Serious Bacterial Infection } \\
\hline BC positive $\%(\mathrm{n})$ & 0 & $1.6(1)$ & $2.1(2)$ & $1.8(2)$ & 0 & $1.4(5)$ \\
\hline Bacterial meningitis \% (n) & 0 & 0 & 0 & 0 & 0 & 0 \\
\hline UTI \% (n) & $8.3(2)$ & $4.9(3)$ & $2.1(2)$ & $1.8(2)$ & $1.4(1)$ & $2.7(10)$ \\
\hline Any SBI \% (n) & $0.5(2)$ & $1.1(4)$ & $1.1(4)$ & (4) & (1) & $4.1(15)$ \\
\hline
\end{tabular}

Abbreviations: POCT, point of care testing; NPA, nasopharyngeal aspirate; OR, odds ratio; LP, lumbar puncture; UTI, urinary tract infection; SBI, serious bacterial infection (positive blood culture, urine culture or CSF).

${ }^{*}$ Suprapubic aspirate or catheter urine collection 
Figure 1:
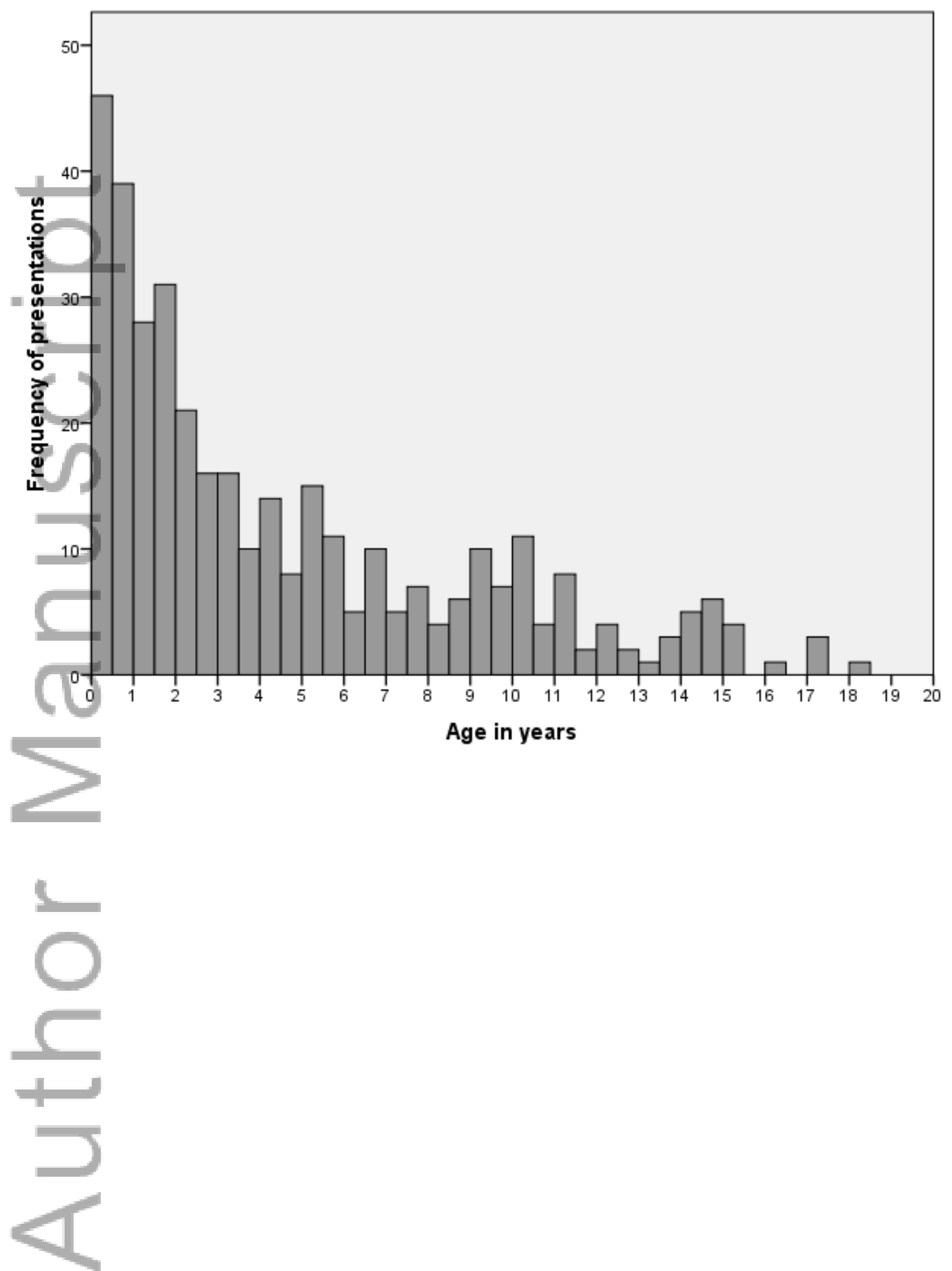

This article is protected by copyright. All rights reserved. 
Figure 2:

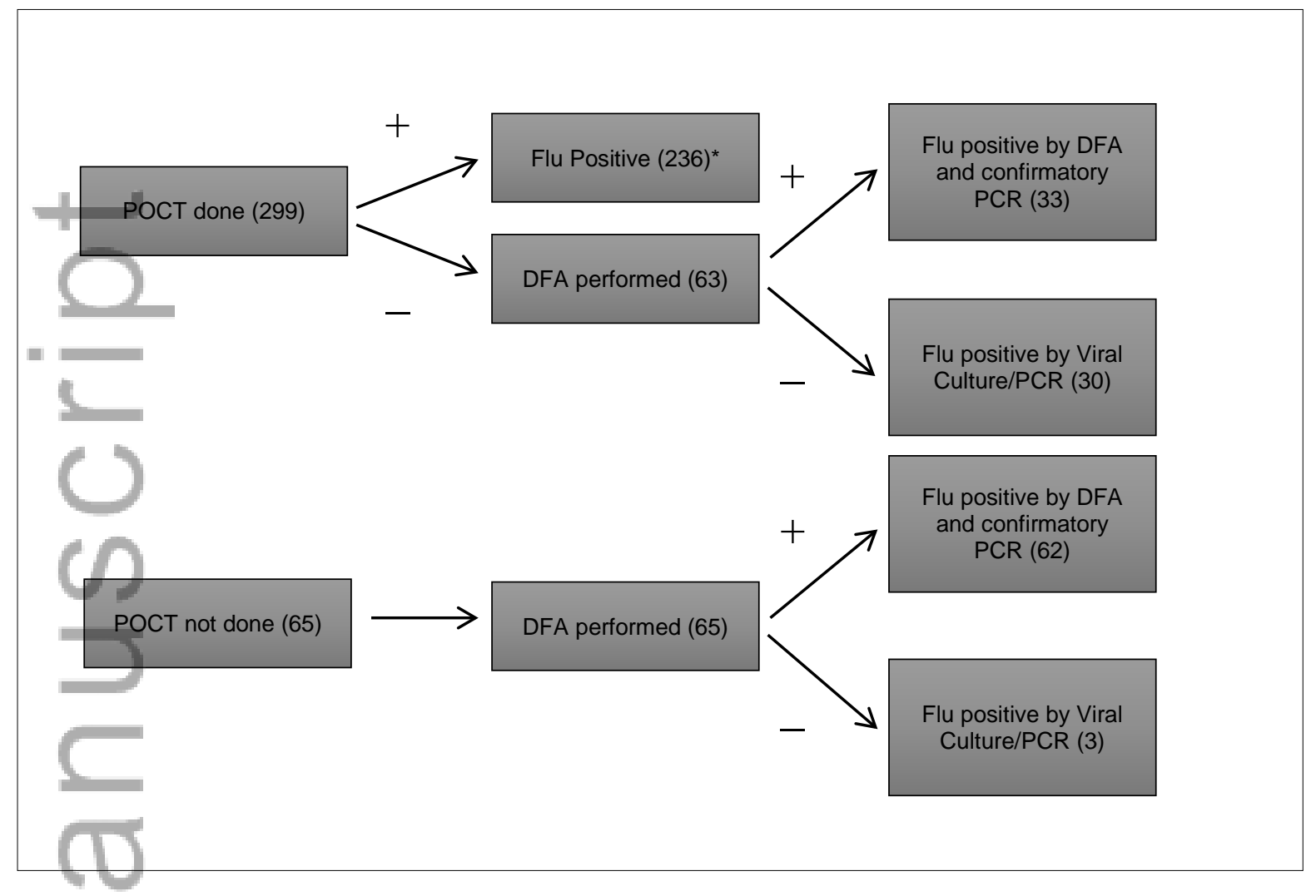

Abbreviations: POCT, Point-of-care test; DFA, Direct Fluorescent Antibody testing; PCR, Polymerase Chain Reaction test. * Three influenza positive patients diagnosed by POCT were also positive DFA testing. 
Figure 3:

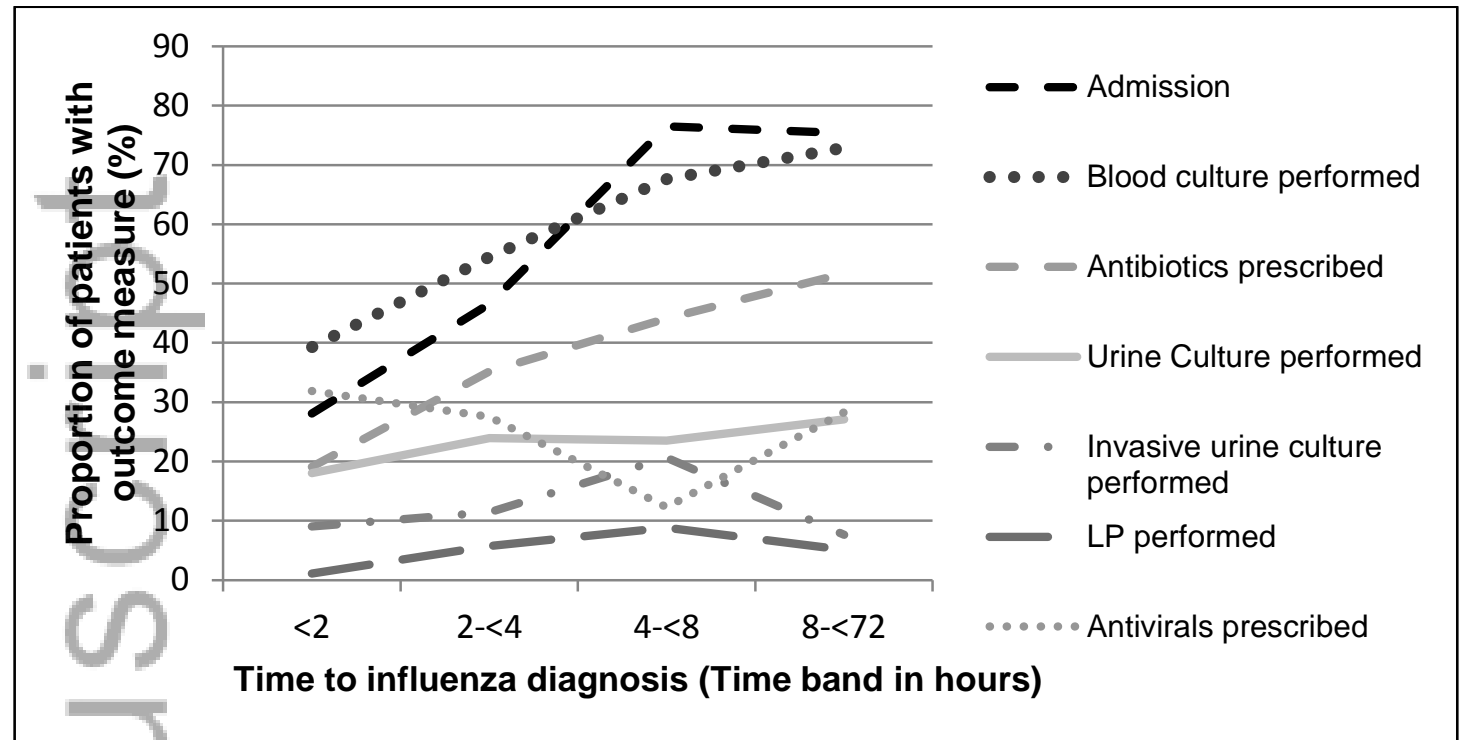

Patients allocated into time bands of "time to influenza diagnosis" (from commencement of medical assessment until influenza test result available) and the proportion with each outcome measure in each time band was calculated.
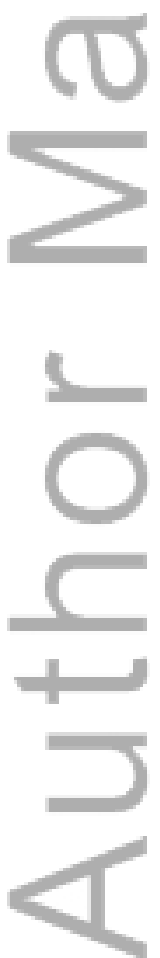

This article is protected by copyright. All rights reserved. 


\section{References}

1. Antonova EN, Rycroft CE, Ambrose CS, Heikkinen T, Principi N. Burden of paediatric influenza in Western Europe: a systematic review. BMC Public Health. 2012;12:968.

2. Chiu C, Dey A, Wang H, et al. Vaccine preventable diseases in Australia, 2005 to 2007. Commun Dis Intell. 2010;34 Supp:S1-167.

3. Iskander M, Kesson A, Dwyer D, et al. The burden of influenza in children under 5 years admitted to the Children's Hospital at Westmead in the winter of 2006. J Paediatr Child Health. 2009;45(12):698-703.

4. Ploin D, Gillet Y, Morfin F, et al. Influenza burden in febrile infants and young children in a pediatric emergency department. Pediatr Infect Dis J. 2007;26(2):142-7.

5. Poehling KA, Edwards KM, Griffin MR, et al. The burden of influenza in young children, 2004-2009. Pediatrics. 2013;131(2):207-16.

6. Lester-Smith D, Zurynski YA, Booy R, Festa MS, Kesson AM, Elliott EJ. The burden of childhood influenza in a tertiary paediatric setting. Commun Dis Intell. 2009;33(2):209-15.

7. Khandaker G, Heron L, Rashid H, et al. Comparing the use of, and considering the need for, lumbar puncture in children with influenza or other respiratory virus infections. Influenza Other Respi Viruses. 2012;7(6):932-7.

8. Abanses JC, Dowd MD, Simon SD, Sharma V. Impact of rapid influenza testing at triage on management of febrile infants and young children. Pediatr Emerg Care. 2006;22(3):145-9.

9. Benito-Fernandez J, Vazquez-Ronco MA, Morteruel-Aizkuren E, Mintegui-Raso S, SanchezEtxaniz J, Fernandez-Landaluce A. Impact of rapid viral testing for influenza A and B viruses on management of febrile infants without signs of focal infection. Pediatr Infect Dis J. 2006;25(12):11537.

10. Bonner AB, Monroe KW, Talley LI, Klasner AE, Kimberlin DW. Impact of the rapid diagnosis of influenza on physician decision-making and patient management in the pediatric emergency department: results of a randomized, prospective, controlled trial. Pediatrics. 2003;112(2):363-7.

11. Doan QH, Kissoon N, Dobson S, et al. A Randomized, Controlled Trial of the Impact of Early and Rapid Diagnosis of Viral Infections in Children Brought to an Emergency Department with Febrile Respiratory Tract Illnesses. J Pediatr. 2009;154(1):91-5.

12. Esposito S, Marchisio P, Morelli P, Crovari P, Principi N. Effect of a rapid influenza diagnosis. Arch Dis Child. 2003;88(6):525-6.

13. Iyer SB, Gerber MA, Pomerantz WJ, Mortensen JE, Ruddy RM. Effect of point-of-care influenza testing on management of febrile children. Acad Emerg Med. 2006;13(12):1259-68.

14. Mintegi S, Garcia-Garcia JJ, Benito J, et al. Rapid influenza test in young febrile infants for the identification of low-risk patients. Pediatr Infect Dis J. 2009;28(11):1026-8.

15. Blaschke AJ, Shapiro DJ, Pavia AT, et al. A National Study of the Impact of Rapid Influenza Testing on Clinical Care in the Emergency Department. J Pediatric Infect Dis Soc. 2014;3(2):112-8.

16. Khandaker G, Zurynski Y, Ridley G, et al. Clinical epidemiology and predictors of outcome in children hospitalised with influenza A(H1N1)pdm09 in 2009: a prospective national study. Influenza Other Respir Viruses. 2014;8(6):636-45.

17. Australian Government Department of Health and Ageing. Australian Health Management Plan for Pandemic Influenza 2009 [Accessed 05/12/2014]. Available from:

http://www.flupandemic.gov.au/internet/panflu/publishing.nsf/Content/B11402BB723E0B78CA25781 E000F7FBB/\$File/ahmppi-2009.pdf.

18. Australian Department of Health and Ageing. Australian Immunisation Handbook. 9th ed. Canberra, Australia: Australian Government; 2008.

19. Andresen DN, Kesson AM. High sensitivity of a rapid immunochromatographic test for detection of influenza A virus 2009 H1N1 in nasopharyngeal aspirates from young children. J Clin Microbiol. 2010;48(7):2658-9.

20. Krief WI, Levine DA, Platt SL, et al. Influenza Virus Infection and the Risk of Serious Bacterial Infections in Young Febrile Infants. Pediatrics. 2009;124(1):30-9. 
21. Smitherman HF, Caviness AC, Macias CG. Retrospective review of serious bacterial infections in infants who are 0 to 36 months of age and have influenza A infection. Pediatrics. 2005;115(3):710-8.

22. Black S, Shinefield H, Fireman B, et al. Efficacy, safety and immunogenicity of heptavalent pneumococcal conjugate vaccine in children. Pediatr Infect Dis J. 2000;19(3):187-95.

23. Kaplan SL, Mason EO, Wald ER, et al. Decrease of Invasive Pneumococcal Infections in Children Among 8 Children's Hospitals in the United States After the Introduction of the 7-Valent Pneumococcal Conjugate Vaccine. Pediatrics. 2004;113(3):443-9.

24. Black SB, Shinefield HR, Fireman B, Hiatt R, Polen M, Vittinghoff E. Efficacy in infancy of oligosaccharide conjugate Haemophilus influenzae type b (HbOC) vaccine in a United States population of 61,080 children. The Northern California Kaiser Permanente Vaccine Study Center Pediatrics Group. Pediatr Infect Dis J. 1991;10(2):97-104.

25. Peltola H, Kilpi T, Anttila M. Rapid disappearance of Haemophilus influenzae type b meningitis after routine childhood immunisation with conjugate vaccines. The Lancet. 1992;340(8819):592-4.

26. Wilkinson M, Bulloch B, Smith M. Prevalence of Occult Bacteremia in Children Aged 3 to 36 Months Presenting to the Emergency Department with Fever in the Postpneumococcal Conjugate Vaccine Era. Acad Emerg Med. 2009;16(3):220-5.

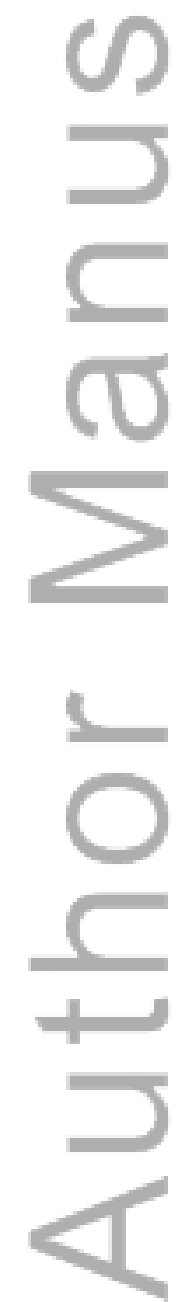




\section{University Library}

\section{- MINER VA ACCESS}

\section{A gateway to Melbourne's research publications}

Minerva Access is the Institutional Repository of The University of Melbourne

\section{Author/s:}

Li-Kim-Moy, J;Dastouri, F;Rashid, H;Khandaker, G;Kesson, A;McCaskill, M;Wood, N;Jones, C;Zurynski, Y;Macartney, K;Elliott, EJ;Booy, R

Title:

Utility of early influenza diagnosis through point-of-care testing in children presenting to an emergency department

\section{Date:}

2016-04-01

\section{Citation:}

Li-Kim-Moy, J., Dastouri, F., Rashid, H., Khandaker, G., Kesson, A., McCaskill, M., Wood, N., Jones, C., Zurynski, Y., Macartney, K., Elliott, E. J. \& Booy, R. (2016). Utility of early influenza diagnosis through point-of-care testing in children presenting to an emergency department. JOURNAL OF PAEDIATRICS AND CHILD HEALTH, 52 (4), pp.422-429. https:// doi.org/10.1111/jpc.13092.

Persistent Link:

http://hdl.handle.net/11343/291137 